\title{
Seismic-resistant building practices resulting from Local Seismic Culture
}

\author{
J. Ortega \& G. Vasconcelos \\ ISISE, Faculty of Engineering, University of Minho, Guimarães, Portugal \\ M.R. Correia \\ CI-ESG, Escola Superior Gallaecia, Vila Nova de Cerveira, Portugal
}

\begin{abstract}
Considering that vernacular architecture may bear important lessons on hazard mitigation, this chapter focuses on the European Mediterranean countries and studies traditional seismic-resistant architectural elements and techniques that local populations developed to prevent or repair earthquake damage. This area was selected as a case study because, as a highly seismic region, it has suffered the effect of many earthquakes along the history and, thus, regions within this area are prone to have developed a Local Seismic Culture. After reviewing seismic resistant construction concepts, a wide range of traditional construction solutions that, in many cases, have shown to improve the seismic performance of vernacular constructions of these regions is presented, as a contribution to the general overview of retrofitting building systems provided in this book. The main motivation is that most of these techniques can be successfully applied to preserve and to retrofit surviving examples without prejudice for their identity.
\end{abstract}

\section{INTRODUCTION}

The present chapter deals with vernacular architecture earthquake preparedness, and the methods adopted by local communities to repair and restore their dwellings in the Mediterranean region. Being an important seismic area within Europe, since the MediterraneanHimalayan belt is responsible for $15 \%$ of the world seismic activity, Mediterranean communities have been exposed to long-term important recurrent earthquake hazard along the history and, subsequently, had to adjust to this risk, and had to make decisions, implementing plans and taking action for the protection of their built-up environment.

These efforts made by local populations led to the development of a Local Seismic Culture (Ferrigni, 1990). European Mediterranean regions, where local population have undertaken preventive measures aiming at minimising future losses in following earthquakes, gave rise to rather similar traditional seismic-resistant construction techniques. This is largely due to the traditional cultural connections between ancient and modern communities around the sea, and the fact that, because of the similar climate and geology, they share similar vernacular housing typologies, structural systems and materials.

Therefore, this chapter presents a comprehensive overview of the most common seismic-resistant provisions that can be traditionally identified in European Mediterranean vernacular architecture, particularly in Italy (Pierotti, 2001), Greece (Touliatos, 1992) and Turkey (Homan, 2004). These seismic resilient local building practices concern just some basic structural members of the building, or consist of an entire building structural system. In any case, the most successful ones have lasted for centuries, surviving numerous seismic events and proving their validity. As a sort of natural selection, if something has become traditional, it is because it has been effective in resisting past seismic events in the region and, more important, it can resist seismic events in the future.

\section{CHARACTERISTICS OF VERNACULAR SEISMIC-RESISTANT CONSTRUCTIONS}

Traditionally, the best and costliest materials, as well as the most advanced techniques, were traditionally reserved for temples and monumental buildings, as they were the buildings that were conceived to last over time. The sturdiest types of masonry were used to build bulky constructions, able to resist very large earthquakes, based solely on the strength, rigidity and good quality of the materials. However, the basic seismicresistant concepts that eventually took root in the vernacular building culture of a seismic prone region had to make use of affordable and locally available materials. In addition, they also had to develop simple practices concerning construction aspects affecting the seismic vulnerability of their buildings other than the quality of the materials.

For example, regarding the geometry of their buildings, the main requirement is that buildings should be simpler, in order to have more seismic stability. The building should present symmetry in terms of 
mass and stiffness, both in plan and elevation, in order to reduce torsion; low height to base ratio, in order to minimise the tendency to overturn; and a compact plan with a low length to width ratio, in order to have similar resistance in every direction. Uniform elevation with equal floor heights and a low centre of gravity also reduce the building's vulnerability. The number of openings should be reduced, carefully and symmetrically distributed, with their frames properly reinforced.

With respect to construction solutions and materials, local populations acknowledged and accepted that it is not economically viable to construct every building to resist earthquakes without suffering deformation and damage, but the collapse of the structure must always be avoided. Thus, in order for the building to be able to deform while keeping the building standing, ductile materials, such as timber, are required, so that they can resist the tensile stresses. Enhancing the deformability of the structure requires that the load-carrying components are well coupled together, in order to form closed contours in vertical and horizontal planes. This way, the stress concentrations are avoided and forces are transmitted from one component to another even through large deformations. Another key aspect for a building to sustain damage without total collapse is the redundancy of the structural elements, so that failure of certain members is tolerated.

Lastly, the building seismic vulnerability will be highly reduced if it is in a good state of conservation, requiring proper maintenance and adequate post-earthquake repair and strengthening works. The potential resilience to earthquakes of vernacular constructions presenting earthquake resistant characteristics is considerable and worthy to be studied and recognised. However, due to the common lack of maintenance, vernacular constructions are extremely vulnerable to earthquake damage and need awareness and protection.

\section{TRADITIONAL SEISMIC RESISTANT BUILDING PRACTICES}

Although many of the following traditional practices may not have been originally conceived as earthquake resistant measures, they are actually efficient in enhancing the structural performance of buildings during earthquakes. Their use was spread out along the Mediterranean countries because, after an earthquake, reconstruction works tended to copy those designs that withstood the event and thus, these practices can be recognised as evidences of a Local Seismic Culture. However, that is also the reason why some of them can also be found in regions with low earthquake hazard.

\subsection{Elevation configuration}

As previously stated, a low centre of gravity reduces the building's vulnerability because it provides greater stability to the structure by concentrating more mass towards the ground. For that purpose, scarp walls have been used since the earliest civilizations, as they decrease the thickness of the upper floors' walls, and provide light timber floors. Another very common practice in regions, where stone and timber are available local materials, such as in the city of Xanthi, in Greece (Papadopoulos, 2013), was the combination of two different structural systems. The ground floor is built with heavy stone masonry walls, while a timber frame structure is used in the upper floors. The use of lighter stone masonry in upper floors is also a common technique in many masonry constructions in Italy (Ferrigni et al., 2005).

\subsection{Use of timber elements}

A very common vernacular practice that can be observed in many seismic prone areas of the Eastern Mediterranean countries, such as Greece (Vintzileou, 2011) and Turkey (Homan, 2004), consists of imparting ductility to the masonry wall by inserting timber elements within the wall, as reinforcement. The good seismic performance of this practice has been reported in many past earthquakes, such as in the 1999 Marmara earthquake in Turkey (Gülhan and Güney, 2000).

This technique dates as far back as the Minoan civilization in Bronze Age Crete. When applied within the rubble and ashlar masonry walls, these embedded timber reinforcements were, in many cases, sophistically arranged constituting a structural timber frame, extending from the foundations to the roof. In some other cases, just a few vertical or horizontal timber elements were inserted inside the walls, sometimes consisting of a rough timber grid of horizontal timber trunks or tree branches, lying longitudinally and transversally at different levels of the wall. Due to its continued use during the last 35 Centuries, this practice has nowadays become endemic of the vernacular way of building in these regions, as part of a Local Seismic Culture (Fig. 1).

The insertion of timber elements within the masonry is clearly a strengthening method, as their excellent tensile properties allow them to constitute successful slip planes and both, vertical and horizontal, shock absorbers, helping to dissipate relevant amounts of energy. In addition, by confining the masonry, they enhance its bearing capacity, its compressive strength, its shear strength, and its deformability properties
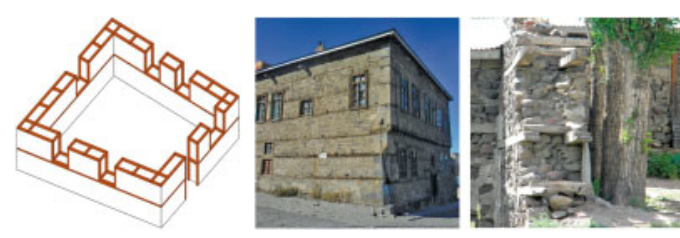

Figure 1. Typical timber reinforcements of traditional houses in: (left) Northern Greece (Touliatos, 2001); (right and middle) Erzurum, Turkey, known as hatıl (Inan, 2014). 
(Vintzileou, 2008). Another main function of this technique is the fact that, by introducing timber elements at different levels within the height of the walls, longitudinally and transversally, it connects the different structural elements among themselves, tying the building and enhancing its box-behaviour. Moreover, when applied in multiple-leaf masonry walls, these longitudinal and transverse timber beams can help to increase the integrity of the entire wall, by tying the faces and preventing them from delamination.

\subsubsection{Structural timber frames: Historical earthquake protection regulations}

There are several particular cases throughout history, in which devastating earthquakes induced the development of official regulations for the reconstruction of the city through a post-earthquake concerted response that involved the government of that time. Some of these regulations included the design and introduction of new seismic-resistant construction systems, all of them based on the use of a structural timber frame. The most well-known example is the Pombalino building system, introduced in Portugal after the destructive 1755's Lisbon earthquake.

Nevertheless, this took place also in Calabria, in Italy, after the 1783's earthquake. A similar earthquake resistant system was developed after a scholarly commission was appointed by the government to study earthquakes, and to recommend reconstruction policies (Tobriner, 1983). A better seismic behaviour of timber structures during the earthquake was reported, forming the basis of the new system, known as casa baraccata. Timber elements included vertical, horizontal, diagonal bracing members, and transverse components, linking the two wall faces. Local communities embraced this system, acknowledging its good seismic-resistant characteristics, and they have continued to use them, becoming part of the traditional way of building of those regions and their Local Seismic Culture. Several ruined buildings testify the application of this system in reconstructed towns and cities in Calabria (Fig. 2).

Another example occurred in the island of Lefkas, in Greece, where the periodic recurrence of earthquakes led the inhabitants to improve the seismic resistance
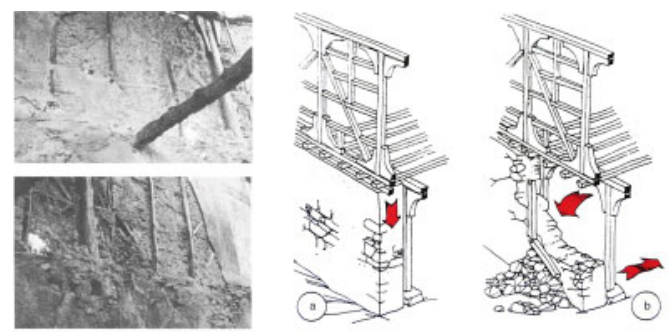

Figure 2. (left) Casa baraccata timber frame system in a vernacular construction in Calabria (credits: Tobriner, 1983); (right) Dual bearing structure in Lefkas Island, Greece (credits: Ferrigni et al., 2015). of their constructions, and to work out an indigenous structural system that effectively resisted earthquake loading. This system emerged from a long traditional practice, being a very illustrative example of the development of a Local Seismic Culture (Porphyrios, 1971). Additionally, after the 1825 's destroying earthquake, its use was also imposed by the English government, who occupied the island at the time (Touliatos, 1992).

Its most significant seismic resistant characteristic is the structural redundancy. On the ground floor, the buildings are constructed with load bearing thick masonry walls, but an independent timber frame is also present as a secondary structure. This way, the masonry walls can collapse in the event of an earthquake, which will tend to be thrown toward the exterior, because of the presence of the timber frame in the interior. The timber structure will not collapse, keeping the building standing and the roof intact, since it is supported by the timber frame, and thus, protecting the people inside the building. The masonry walls can be easily and rapidly repaired (Fig. 2).

Additionally, the upper floor is built with a highly perfected timber frame. So the weight is reduced, and the centre of gravity is lowered. The timber frame is composed by vertical, horizontal and diagonal members, forming different compartments filled with bricks held together with mortar. Timber elbows are also used to stiffen the connections between the vertical and horizontal elements, and to maintain the geometrical integrity of the structure. Partition walls are also built entirely in timber, and are of negligible weight. Today, this system is still common and widespread in the island, and has proven to behave well against earthquakes, such as in the 2003's earthquake, when none of them suffered total collapse, even though there were cases of three-story reinforced concrete buildings that did (Karakostas et al., 2005).

\subsection{Connection between structural elements}

Proper connections are essential for the vertical structural elements not to behave independently, ensuring the box behavior of the building so that the horizontal forces can be absorbed by walls in the same plane. This is one of the most effective measures against earthquakes, as the in-plane resistance of the masonry is significantly higher than its out-of-plane resistance (Lourenço et al. 2011). However, a full multi-connected box is often very far from reality in vernacular architecture. In many cases, single walls work separately, having to bear, by themselves, the portion of load that acts on them.

Traditionally, quoins were used to improve the connections between walls at the corners. The best quality, large and squared stone blocks were used at the corners to improve the adequate connection of the façades of the building, and to prevent their overturn, by creating efficient overlapping of the ashlars with the rest of the wall. They are a very common element in the stone masonry vernacular architecture in the Mediterranean countries. 


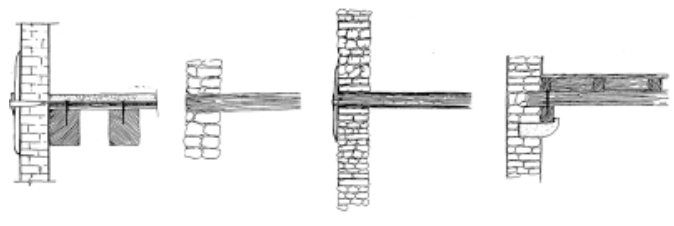

Figure 3. Examples of common reinforced floor-to-wall connections found in the Veneto region, Italy (credits: Barbisan \& Laner, 1995).

Improving wall-to-floor and wall-to-roof connections has also been always a concern for builders in seismic areas. Many technical construction manuals arose during the nineteenth and early twentieth century in Italy, describing detailed methods on how to properly connect the floors to the vertical masonry walls (Barbisan and Laner, 1995), also acknowledging the importance of this aspect in seismic resistant building systems. As technical solutions, they were not commonly applied in vernacular architecture, but other traditional devices, which tried to copy them and to achieve the same effect, can be usually found.

Reinforced floor and roof-to-wall connections are traditionally achieved using wooden wedges to ensure a tight connection between the walls and the floor, or roof joists that pierce them. Also, transition elements, such as timber resting plates, or stone brackets, are applied to improve these connections. Metallic anchoring devices, such as metal brackets or steel straps, can also be found in vernacular architecture reinforcing the connections (Fig. 3).

\subsubsection{Ties}

The application of ties, making effective links to hold together the different parts of masonry structures, might be the most common ancient strengthening practice adopted to ensure the box behaviour of the building, and to improve its structural integrity. Given the fact that ties are relatively easy to implement in existing structures, before or after earthquake damage, they have been widely used for many centuries, and they can be systematically observed in highly seismic regions of Mediterranean Europe. They are introduced as a reinforcement measure, used to connect perpendicular load bearing walls, load bearing walls to interior walls, parallel load bearing walls, walls to floors and walls to roofs.

Ties connecting perpendicular walls provide lateral bracing. Ties connecting parallel walls are intended to avoid their out-of-plane collapse, but also to constrain the floors, facilitating the transfer of the load to the bracing orthogonal walls in the same plane, and improving the overall performance of the system. Actually, a common practice to vernacular architecture is the use of their own timber floor joists as ties between parallel walls. Ties have to be well restrained at the ends, commonly by steel anchor plates, in the case of steel tie rods, or, by wedges, in the case of wooden tie beams.

\subsubsection{Traditional jointing system}

An important feature about the connections is the type of joints used. In vernacular architecture, the jointing system for wooden structural elements has been traditionally made through flexible housed joints and wedges, which were actually an effective energy dissipation system in the event of an earthquake, because, while allowing the tightening of the joints, they effectively act as pin joints, also allowing some movement within the joints.

\subsection{Stabilisation of floors and roofs}

Concerning the stabilisation of roofs and floors, the traditional approach has consisted of improving their diaphragmatic behaviour by reducing their excessive deformability, and by adding in-plane and flexural stiffness. In this way, they are able to transfer the loads for a given direction of motion from the out-of-plane walls to the in-plane walls. This has been traditionally achieved through diagonal bracing and triangulation. A significant example, illustrating a Local Seismic Culture, can be found in Galaxidi, on the seismically hazardous Corinthian Bay in Greece, where the typical structural system applied consists of stiffening the ceiling through triangulation and proper coupling with the timber reinforcing components, located on top of the masonry walls (Touliatos, 2001).

\subsection{Reinforcement of the openings}

Seismic-resistant vernacular constructions usually present a reduced number of openings, and symmetry in their layout. Closed-up openings can be commonly identified in seismic prone areas, showing the inhabitants' awareness of the vulnerability of these elements. Several ways of reinforcing openings can be commonly observed, such as the use of relieving or discharging arches inserted within the wall, over the openings lintels. These are intentioned to lighten the load of the underlying element, and to better distribute the load path. Windows and doorframes are also traditionally reinforced with big stone or timber lintels, aimed at promoting enough resistance to bending stresses. Brackets are useful for reducing the free span of the lintel; and jambs are necessary because of the strong compression forces that concentrate in the bearing area of the lintel.

\subsection{Elements neutralizing the horizontal forces exerted by the building}

Different types of reinforcement elements, such as buttresses or counterforts, have been also widely used throughout history, since the earliest civilizations, in order to neutralise the seismic horizontal forces. These elements provide a contrasting effect against the buckling tendency of a wall, and are very common in most seismic prone regions in the Mediterranean (Pierotti, 2001).

Buttresses are the most common strengthening measure, aimed at counteracting the horizontal forces 
exerted by the building during earthquakes. These are also very commonly recognised in vernacular constructions. They consist of pier-like, massive local additions, generally built of masonry, whose working principle is to counter the rotation of the façade thanks to their sheer mass. They can be built at the same time as the building, as a deliberated feature, or they can be added on to older masonry as a reinforcement measure.

\subsubsection{Urban reinforcing measures}

In urban environments, other elements that perform a similar reinforcement task are the reinforcement arches, also known as buttressing arches. These are usually made of masonry and span the street, joining facing buildings. These alterations of the historical built-up areas effectively enhance the interaction between buildings, and lead to the collaborative action of neighbouring constructions and structural elements, enabling the horizontal movements to be redistributed among their vertical walls.

Urban reinforcement arches and buttresses can eventually transform into other urban elements that accommodate new uses, since their construction results in an increase in volume and new space available for the building. Therefore, these added structures can eventually become habitable and turn into loggias, vaulted passageways or arcades, fulfilling, simultaneously, a structural and a functional role, with the addition of new paths and rooms. Sometimes other urban structures, such as external stairs, can also fulfil a similar role, counteracting the rotation of the walls. These reinforcements are the characteristic historical solution to avoid the development of out-of-plane mechanisms, at an urban level, in villages built mainly of stone masonry, such as the Italian. These have become, indeed, part of their historical fabric (Fig. 4). They are a distinctly reinforcement measure because, when added to the buildings, they took space from the public use, narrowing the public space with a subsequent discomfort for the inhabitants and, thus, showing their seismic concern.

\subsection{Position within urban fabric}

Finally, the interaction between buildings has also a significant influence in their seismic performance. Different responses to the seismic action by neighbouring buildings can cause damage in the connecting borders, where stress concentrations are present. Different stiffness of the bodies like, for instance, reinforced concrete buildings adjacent to masonry house, introduce a severe risk of hammering actions to take place. However, an interaction between buildings can also have beneficial effects, and even prevent earthquake damage. Actually, the common vernacular tradition consists of making the neighbouring buildings to collaborate and to reinforce each other. Historical city centres are usually composed of many single buildings adjacent to one another, and structurally connected, thus achieving a structural continuity, and accordingly, reacting uniformly to seismic loading.
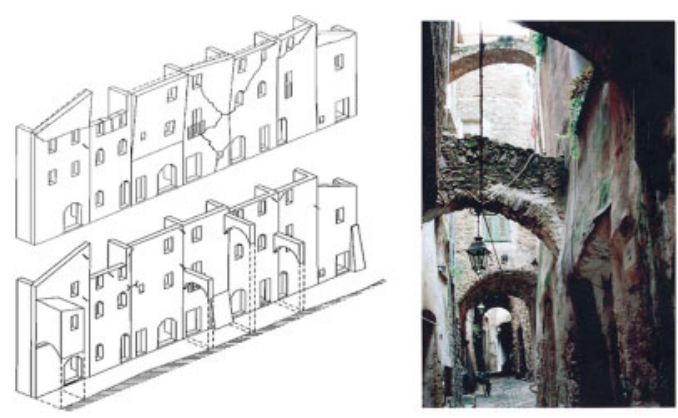

Figure 4. Building complexes in: (left) Anavatos village in Chios Island, Greece (Efesiou, 2001); (right) Mandraki, in Nysiros Island, Greece (credits: Ferrigni et al., 1995).
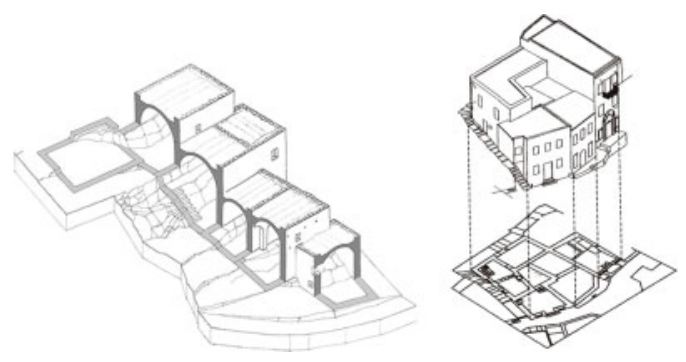

Figure 5. (left) Historical solution to out-of-plane mechanisms at an urban level (Borri et al., 2001); (right) Reinforcement arches in Dolce-Aqua, Italy (credits: Ferrigni et al., 1995).

There are several examples of strategies to resist earthquakes involving their position at the urban fabric (Fig. 5). In Chios Island, Greece, buildings were usually constructed in contact to one another, trying to make them to cooperate and to reinforce each other, by equilibrating the horizontal forces exerted by the domes, and providing more stable dynamic units (Efesiou, 2001). In Mandraki, main village on Nysiros Island, in Greece, the intricate composition of the historical building complexes also ensures a unified behaviour under horizontal loading (Touliatos, 2001).

\section{CONCLUSIONS}

This paper provides an overview of the most common seismic-resistant provisions, traditionally used in the vernacular architecture across the Mediterranean Sea, focusing on those construction characteristics that most influence their seismic behaviour: geometry, materials and construction solutions, openings characteristics, use of reinforcement elements and position within urban fabric. A wide range of traditional solutions, where each of these aspects can be observed, together with a cohesion in the use of specific seismic-resistant features, are present in some of the Mediterranean countries.

Even though associating changes or innovations in the construction techniques to the existence of a 
seismic culture is difficult, illustrative examples of the development of a Local Seismic Culture have been reviewed, such as the characteristic constructive system that arose in Lefkas Island, in Greece.

As reported in previous seismic events, wellconstructed vernacular buildings showing traditional seismic-resistant features can present far less vulnerability than expected. Research in these traditional practices is justified, because they can eventually be applied as strengthening measures for existing and in-use vernacular architecture. Besides, they are in accordance with modern principles of preservation, regarding compatibility and authenticity, since they use similar materials and techniques than the original structures. Local communities should be encouraged to readopt some of these techniques, in order to reduce the seismic vulnerability of their constructions.

\section{REFERENCES}

Barbisan, U. \& Laner, F. (1995). Wooden floors: part of historical antiseismic building systems. Annali di Geofisica 38, 775-784.

Borri, A., Avorio, A. \& Cangi, G. (2001). Guidelines for seismic retrofitting of ancient masonry buildings. Revista Italiana di Geotecnica 4, 112-121.

Efesiou, I. (2001). Constructional analysis of the local structural system of the historic settlements of Anavatos in Chios island. In International Seminar of Restoration of Historic Buildings in Seismic Areas: The Case of Settlements in the Aegean. Lesvos Island, Greece.

Ferrigni, F. (1990). À la recherché des anomalies qui protégent. Actes des Ateliers Européens de Ravello, 19-27 Novembre 1987. Ravello: PACT Volcanologie et Archéologie \& Conseil de L'Europe.

Ferrigni, F., Helly, B., Mauro, A., Mendes Victor, L., Pierotti, P., Rideaud, A. \& Teves Costa, P. (2005).Ancient Buildings and Earthquakes. The Local Seismic Culture approach: principles, methods, potentialities. Ravello: Centro Universitario Europeo per i Beni Culturali, Edipuglia srl.

Gülhan, D. \& Güney, I.Ö. (2000). The Behavior of Traditional Building Systems Against Earthquakes and its Comparison to Reinforced Concrete Frame Systems; Experiences of Marmara Earthquake Damage Assessment Studies in Kocaeli and Sakarya. International Conference on the
Seismic Performance of Traditional Buildings. Istanbul, Turkey.

Homan, J. (2004). Seismic Cultures: Myth or Reality? Second International Conference on Post-Disaster Reconstruction: Planning for Reconstruction. Coventry, UK.

Inan, Z. (2014). Runner beams as building element of masonry walls in Eastern Anatolia, Turkey. In M. Correia, S. Rocha \& g. Carlos (Eds.), Vernacular Heritage and Earthen Architecture: Contributions for Sustainable developments: 721-726. London: Taylor \& Francis Group.

Karakostas, C., Lekidis, V., Makarios, T., Salonikios, T., Sous, I. \& Demosthenus, M. (2005). Seismic response of structures and infrastructures facilities during the Lefkada, Greece earthquake of 14/8/2003. Engineering Structures 27(2), 213-227.

Lourenço, P.B., Mendes, N., Ramos, L.F. \& Oliveira, D.V. (2011). On the analysis of masonry structures without box behavior. International Journal of Architectural Heritage: Conservation, Analysis, and Restoration 5(4-5), 369-382.

Papadopoulos, M.L. (2013). Seismic Assessment of Traditional Houses in the Balkans - Case Studies in Xanthi. Journal of Civil Engineering and Science 2(3): 131-143.

Pierotti, P. (2001). Culture sismiche locali. Pisa: Edizioni Plus Università di Pisa.

Porphyrios, D.T.G. (1971). Traditional Earthquake-Resistant Construction on a Greek Island. Journal of the Society of Architectural Historians 30(1): 31-39.

Tobriner, S. (1983). La Casa Baraccata: Earthquake-Resistant Construction in 18th-Century Calabria. Journal of the Society of Architectural Historians 42(2): 131-138.

Touliatos, P.G. (1992). Traditional aseismic techniques in Greece. In L. Mendes Victor (ed.), Proceedings of the International Workshop "Les systemes nationaux faces aux seismes majeurs". Lisbon: Centro de Geofisica, Universidade de Lisboa.

Touliatos, P.G. (2001). The box framed entity and function of the structures: The importance of wood's role. In International Seminar of Restoration of Historic Buildings in Seismic Areas: The Case of Settlements in the Aegean. Lesvos Island, Greece.

Vintzileou, E. (2008). Effect of Timber Ties on the Behavior of Historic Masonry. Journal of Structural Engineering 134(6): 961-972.

Vintzileou, E. (2011). Timber-reinforced structures in Greece: 2500 BC-1900 AD. In Proceedings of the Institution of Civil Engineers (ICE), Structures and Buildings 164(SB3): 167-180. 